\title{
Pensamento Algébrico Funcional em Situações de Comparar Grandezas: um Rastreamento a Partir do Método Clínico
}

\section{Functional Algebraic Thinking Situations of Compare Quantities: a Tracking through the Clinical Method}

\author{
Vinicius Carvalho Beck*a; João Alberto da Silva ${ }^{\mathrm{b}}$; Cristina Cavalli Bertolucci ${ }^{\mathrm{b}}$ \\ anstituto Federal Sul-Rio-Grandense, Campus Pelotas. RS, Brasil.

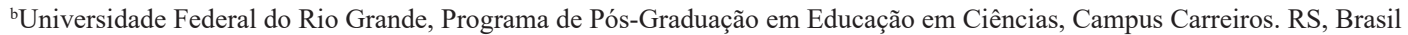 \\ *E-mail: contato.viniciusbeck@gmail.com
}

\begin{abstract}
Resumo
O objetivo deste trabalho foi rastrear traços de pensamento algébrico funcional em problemas que envolvem o ato de comparar grandezas. O Método Clínico de Manipulação e Formalização, proposto e utilizado originalmente pela equipe de Jean Piaget, é utilizado neste trabalho para coleta e análise de dados. Os participantes da pesquisa são estudantes de escolas públicas do interior do Rio Grande do Sul, com idades entre seis e oito anos. Para conhecermos como pensam os sujeitos sobre o tema proposto, realizou-se um experimento com manipulação concreta, conduzido a partir de um roteiro de entrevista semiestruturada. O experimento realizado consistiu no lançamento de dois dados, um pelo participante e outro pelo pesquisador. Após o lançamento, o pesquisador fez algumas perguntas comparando os resultados dos dois dados. Com base em estudos precedentes, partimos da hipótese de que alguns estudantes adotariam a estratégia de previsão seguida por contagem. A novidade que encontramos, em termos de estratégias, foi o uso indiscriminado de operações aritméticas, isto é, operações como adição e tomar o número maior são utilizadas, sem uma análise mais aprofundada da estrutura do problema, e do significado de expressões tais como a mais e a menos nos enunciados. De acordo com estudos precedentes, e com os resultados da presente pesquisa, podemos dizer que a contagem é um procedimento fundamental para que habilidades algébricas possam ser trabalhadas desde os anos iniciais de escolaridade.
\end{abstract}

Palavras-chave: Pensamento Funcional. Pensamento Algébrico. Comparar. Método Clínico.

\begin{abstract}
The objective of this work was to trace traces of functional algebraic thinking in problems involving the act of comparing quantities. The Clinical Method of Manipulation and Formalization, proposed and originally used by Jean Piaget's team, is used in this work for data collection and analysis. The participating in the research are students from public schools in the interior of Rio Grande do Sul, aged between six and eight years. In order to know how the subjects think about the proposed theme, an experiment was carried out with concrete manipulation, conducted from a semi-structured interview script. The experiment was the release of two data, one by the participant and the other by the researcher. After the release, the researcher asked some questions comparing the results of the two data. Based on previous studies, we hypothesized that some students would adopt the prediction strategy followed by counting. The novelty we found, in terms of strategies, was the indiscriminate use of arithmetic operations, that is, operations such as addition and taking the largest number are used, without a more in-depth analysis of the structure of the problem, and the meaning of expressions such as more and less in utterances. According to previous studies, and with the results of this research, we can say that counting is a fundamental procedure for algebraic skills to be worked on since the initial years of schooling.
\end{abstract}

Keywords: Functional Thinking. Algebraic Thinking. Compare. Clinical Method.

\section{Introdução}

Desde que o National Council of Teachers of Mathematics (NCTM, 2000) publicou um documento relatando dificuldades de estudantes de vários países na aprendizagem de conceitos algébricos, muitas propostas de abordagem de professores e pesquisadores têm surgido no sentido de se trabalhar com a Álgebra desde o princípio da escolaridade.

A alfabetização matemática por muito tempo esteve focada, sobretudo, na Aritmética, não contemplando eixos temáticos como a Geometria, o Tratamento da Informação ou o Pensamento Algébrico. O Pensamento Algébrico aborda uma série de habilidades que estão diretamente relacionadas a outros eixos, como por exemplo, a identificação de padrões numéricos ou resolução de alguns tipos de problemas, presentes no eixo números e operações, assim como o reconhecimento e classificação de formas geométricas, relacionadas ao eixo da
Geometria (Brasil, 2014).

O objetivo geral do eixo que aborda o pensamento algébrico nos anos iniciais do Ensino Fundamental é "compreender padrões e relações, a partir de diferentes contextos" (BRASIL, 2014, p. 50), possibilitando à criança determinar critérios para ordenar, classificar e agrupar objetos, levando em consideração diferentes atributos e reconhecer padrões de sequências, de formas, de sons ou padrões numéricos simples, com o intuito de completá-las.

Falcão (2003) utiliza a expressão alfabetização algébrica para definir o trabalho com a álgebra desde o início do Ensino Fundamental. Este é um dos primeiros estudos brasileiros abordando a temática do pensamento algébrico de crianças.

Internacionalmente, o trabalho de Blanton e Kaput (2005) é considerado um marco nas pesquisas sobre pensamento algébrico. Segundo estes pesquisadores, existem basicamente 
duas formas de pensamento algébrico: a Aritmética Generalizada e o Pensamento Funcional.

A Aritmética Generalizada está relacionada com os aspectos das operações numéricas elementares que podem ser submetidos a processos mentais de classificação em níveis progressivamente mais complexos. Um exemplo são as propriedades dos números, tais como a comutatividade, a associatividade e a distributividade. Outro exemplo é o significado do sinal de igualdade em expressões numéricas (Carpenter et al., 2005; Stephens \& Wang, 2008), que abre caminho para o bom entendimento do conceito de equação.

O Pensamento Funcional está relacionado com o reconhecimento de padrões em sequências, e também com a construção de regras de associação entre variáveis (Kieran, 2007; Fujii \& Stephens, 2008; Ponte \& Velez, 2011; Silva \& Savioli, 2012). Esta ideia de relação entre variáveis é inspirada no conceito matemático de função, porém em uma abordagem adaptada para os anos iniciais.

Fujii \& Stephens (2008) destacam que o uso apropriado de sequências numéricas pode contribuir para o desenvolvimento do conceito de variável. As sequências são representações iniciais, que ajudam a compreender a ideia de que existem formas possíveis de descrever a variação em certos conjuntos numéricos. Ainda que a variável na forma de símbolo não seja expressamente apresentada, a noção de variação pode ser compreendida a partir das sequências.

Para Kieran (2007), a Álgebra não se restringe a um conjunto de procedimentos envolvendo símbolos alfabéticos, ou um conjunto de técnicas formais específicas. Para ela, a Álgebra também deve ser considerada uma forma de pensar e raciocinar em situações matemáticas, nos mais diversos contextos, concordando com Blanton \& Kaput (2005). Partindo deste ponto de vista, apresentar sequências ou atividades que demandem a ideia de variação numérica também deve ser considerada como atividade algébrica. Isto significa que várias atividades aplicadas aos anos iniciais de escolaridade também possuem potencial para desenvolver o pensamento algébrico.

Nas pesquisas realizadas por Ponte \& Velez (2011), as crianças participantes conseguiram utilizar boas representações para as sequências, prevendo termos próximos do início, e também alguns mais afastados. Ainda que elas não formalizem suas ideias e constatem que estão fazendo uso de variáveis, a forma de pensar das crianças, nesse caso, apresenta traços de pensamento algébrico.

Segundo Silva \& Savioli (2012), ainda que os estudantes não apresentem uma linguagem simbólica para formalizar o pensamento algébrico, eles possuem mecanismos de representação para visualizar a comparação de quantidades, abstraindo algumas relações matemáticas. A comparação de quantidades também pode ser considerada uma importante habilidade para se desenvolver o pensamento algébrico, mais especificamente, o pensamento funcional, de acordo com Beck \& Silva (2015).

O objetivo deste trabalho foi rastrear traços de pensamento algébrico funcional em crianças de seis a oito anos, especificamente investigando como se apresenta esse pensamento em situações de comparar grandezas. Este tipo de situação se caracteriza por apresentar expressões tais como $a$ mais ou a menos no enunciado do problema proposto, exigindo que o sujeito utilize a habilidade de comparar grandezas por meio da previsão de resultados (Beck \& Silva, 2015).

Apesar de estar mais relacionada com uma habilidade aritmética, inclusive em documentos oficiais como a Base Nacional Comum Curricular (BNCC), a qual prevê na habilidade EF01MA03 o desenvolvimento da comparação de quantidades (Brasil, 2020), apresentamos neste trabalho indícios de que são perceptíveis traços do pensamento algébrico nesse tipo de problema, tal como já destacado por Beck \& Silva (2015).

Conforme destacam Blanton \& Kaput (2005), a previsão de resultados é uma das principais habilidades que envolvem o pensamento algébrico. A habilidade de prever resultados a partir de dados conhecidos é utilizada em diversas situações do cotidiano, e por isso deve ser aprimorada em cada uma das etapas da vida escolar.

\section{Situações de Comparar}

Situações de comparar grandezas, em Matemática, são caracterizadas por haver uma relação entre duas grandezas distintas. Para exemplificar, podemos trazer um exemplo dado por Vergnaud (2009, pág. 203): "Paulo tem 8 bolinhas de gude. Tiago tem 5 menos que Paulo. Então, Tiago tem 3". É comum conter expressões tais como a mais ou a menos nesse tipo de situação. Problemas que envolvem a ação de comparar grandezas também estão presentes em avaliações de larga escala, como na Provinha Brasil de Matemática ${ }^{1}$ (INEP, 2020). A Figura 1 apresenta uma questão dessa prova que avalia, dentre outras coisas, a habilidade de comparar do estudante. 
Figura 1 - Questão 13 da Provinha Brasil de Matemática: Teste 2 de 2016

\section{Questão 13}

Professor(a), leia para os alunos SOMENTE as instruções em que aparece o megafone Repita a leitura, no máximo, duas vezes.

Ai) A professora Jane corrigiu 9 trabalhos de Português e 13 trabalhos de Matemática.

Ai) Faça um $X$ no quadradinho que indica quantos trabalhos de Português foram corrigidos a menos do que os de Matemática.
(A) 22
(B) 21
(C) 9
(D) 4

Fonte: INEP (2020)

Beck \& Silva (2015), ao analisar as estratégias utilizadas por estudantes dos anos iniciais do Ensino Fundamental na resolução de problemas aditivos, especificamente em um experimento envolvendo comparação entre grandezas, constataram que os estudantes utilizaram principalmente a estratégia de previsão seguida por contagem. Segundo os autores, antes de realizar o procedimento de contagem, os participantes que obtiveram sucesso na resolução do problema identificaram a relação entre as grandezas por meio de uma regra, uma associação entre as grandezas, e, por conseguinte, a possibilidade de previsão de uma grandeza em função da outra. Daí a expressão previsão seguida por contagem utilizada por esses autores.

Neste trabalho partimos da hipótese de que alguns estudantes, a partir do experimento proposto, adotariam a estratégia de previsão seguida por contagem. No entanto, buscamos aprofundar mais a discussão sobre as estratégias utilizadas em problemas desse tipo, de modo a assumir a hipótese de que outras estratégias poderiam surgir.

Vergnaud (1990, 2009) chama de teoremas-em-ação os esquemas mentais construídos pelo sujeito que apresentam relações de causalidade e que o sujeito acredita ser verdadeiro, ainda que provisoriamente. Ao contrário dos teoremas da Matemática científica, os teoremas-em-ação são estabelecidos por experiência e podem ser atualizados de acordo com novos tipos de experiências.

Nesse sentido, poderíamos dizer que a previsão seguida por contagem se constitui como um teorema-em-ação em situações de comparação. Juntamente com os conceitos-em-

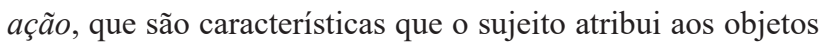
a fim de conceitua-los, os teoremas-em-ação formam o que Vergnaud chama de invariantes operatórios.

Segundo Vergnaud (1990, 2009), um conceito é uma síntese de situações, invariantes operatórios e representações simbólicas que o envolvem. Sendo assim, para que se possa compreender as estratégias e os modos de pensar do sujeito frente a algum objeto do conhecimento, é necessário considerar, dentre outras coisas, as situações com as quais ele está relacionado.

No caso do presente trabalho, as situações que consideramos são situações de comparar, como a situação apresentada na Figura 1. O experimento com o jogo de dados, que propomos neste trabalho, é um representante desse tipo de situação. Desse modo, nos detivemos em analisar os invariantes operatórios e as representações que os estudantes utilizam para resolver esse tipo de problema, o que só poderia ter sido feito mediante pesquisa de campo com sujeitos submetidos a situações de comparar grandezas, daí a justificativa para a realização deste estudo.

Para conhecermos como pensam os sujeitos sobre o tema proposto, realizou-se um experimento com manipulação concreta, conduzido a partir de um roteiro de entrevista semiestruturada. $\mathrm{O}$ experimento realizado consistiu no lançamento de dois dados, um pelo participante e outro pelo pesquisador. Após o lançamento, o pesquisador fez algumas perguntas comparando os resultados dos dois dados. Na Figura 2 é apresentado o roteiro produzido para a aplicação da atividade.

Figura 2 - Roteiro de Perguntas do Experimento 1) Qual número você tirou no dado?

2) Qual número eu tirei no dado?

3) Quem tirou mais?

4) Quanto tirou a mais?

5) Quem tirou menos?

6) Quanto a menos?

7) Como você sabe que a resposta é essa?

8) Um estudante de outra turma tirou o mesmo número que você e deu outra resposta, você acha que ele pode estar certo?

9) Como você fez para chegar na resposta?

10) E é só assim que se pode chegar na resposta ou tem outra maneira?

Fonte: Os autores.

O roteiro da Figura 2 foi precedido por um estudo piloto que necessitou de ajustes na estrutura de algumas perguntas, a fim de se atingir o objetivo proposto. Ao longo das entrevistas, as perguntas sofreram pequenas alterações, mantendo-se a ideia central do roteiro. O objetivo principal foi perceber a capacidade dos estudantes em comparar duas grandezas. Observa-se que a pergunta 8 apresenta uma interpretação alternativa ao sujeito, fazendo-lhe entender o raciocínio de outra criança sobre o mesmo processo. Segundo o referencial metodológico adotado, tal estratégia é chamada de contra argumentação, e é essencial para conhecer como o sujeito compreende uma ideia alternativa ou contrária a sua.

$\mathrm{O}$ que justifica as atividades que propomos neste experimento é o fato de entendermos que o uso de expressões tais como a mais ou a menos permite à criança o acesso 
a situações em que tais expressões não estão ligadas, necessariamente, às operações de adição e subtração. O contato com situações que apresentam conceitos por meio de diferentes representações é fundamental para ampliar o entendimento de um campo conceitual, segundo Vergnaud (2009). Além disso, partimos da hipótese de que este tipo de problema não é usualmente apresentado para as crianças, de modo que seria possível captar pensamentos espontâneos dos participantes.

Ao realizar uma análise a priori, partindo de estudos precedentes sobre o fenômeno estudado, podemos dizer que esperávamos respostas de dois tipos: 1) soma dos números, considerando equivocadamente que o termo a mais da expressão do enunciado fosse entendido como sugestão para uso da operação de adição; 2) diferença dos números, considerando acertadamente o temos a mais como um indicativo de excedente, partindo da ideia de comparação entre grandezas.

\section{Material e Métodos}

Jean Piaget, em suas pesquisas, utilizou um conjunto de técnicas de coleta e análise de dados chamado Método Clínico. Tal método recebeu adequações ao longo de décadas de utilização pelo grupo de pesquisa do autor. $\mathrm{O}$ método consiste em um procedimento para "investigar como as crianças pensam, percebem, agem e sentem, que procura descobrir o que não é evidente no que os sujeitos fazem ou dizem, o que está por trás da aparência de sua conduta, seja em ações ou palavras" (Delval, 2002, p.67). A partir de uma entrevista semiestruturada, denominada entrevista clínica, o experimentador mantém uma "conversa livre" com o sujeito, fazendo perguntas sobre o objeto investigado. A intensão na coleta de dados é conhecer como o entrevistado pensa sobre o tema proposto, tendo-se o cuidado de não sugerir respostas e, sempre que possível, seguir o curso de seu pensamento.

A entrevista pode ser realizada através de uma conversa com o entrevistado ou durante um experimento que envolva manipulação (Disessa, 2007). Neste trabalho optamos por utilizar a versão do método utilizada em pesquisas sobre Epistemologia Genética, especificamente a desenvolvida entre 1940 e 1955. Esta versão do método é descrita em detalhes por Delval (2002), o qual denomina esta fase metodológica como Método Clínico de Manipulação e Formalização (MCMF). Segundo Delval (2002), o MCMF consiste em solicitar ao participante que realize uma tarefa, explicando-a logo após executá-la. A explicação, nesse sentido, é considerada um complemento da ação, e é fonte de informações sobre o percurso do pensamento que o participante mobiliza para realizar a tarefa proposta.

Para a utilização do MCMF é fundamental ter uma ou mais hipóteses iniciais. A partir da delimitação do problema a ser investigado, o passo seguinte é "ter expectativas quanto à forma como o sujeito abordará o assunto que lhe propusermos" (Delval, 2002, p. 82). Nesta pesquisa investigou-se como se apresenta o pensamento algébrico em situações de comparar. Nossa hipótese inicial era de que as crianças utilizariam a previsão de resultados para comparar as grandezas apresentadas, seguida por contagem.

Os participantes da pesquisa são estudantes do primeiro ano de escolas públicas do interior do Rio Grande do Sul, com idades entre seis e oito anos. A intenção desta escolha foi devido ao fato de que crianças nessa idade normalmente estão matriculadas nos anos iniciais do Ensino Fundamental, e, portanto, provavelmente ainda não tiveram contato com problemas formais de Álgebra, ou seja, ainda não aprenderam na escola as representações usuais em problemas que envolvem relações entre variáveis, fórmulas, equações, etc.

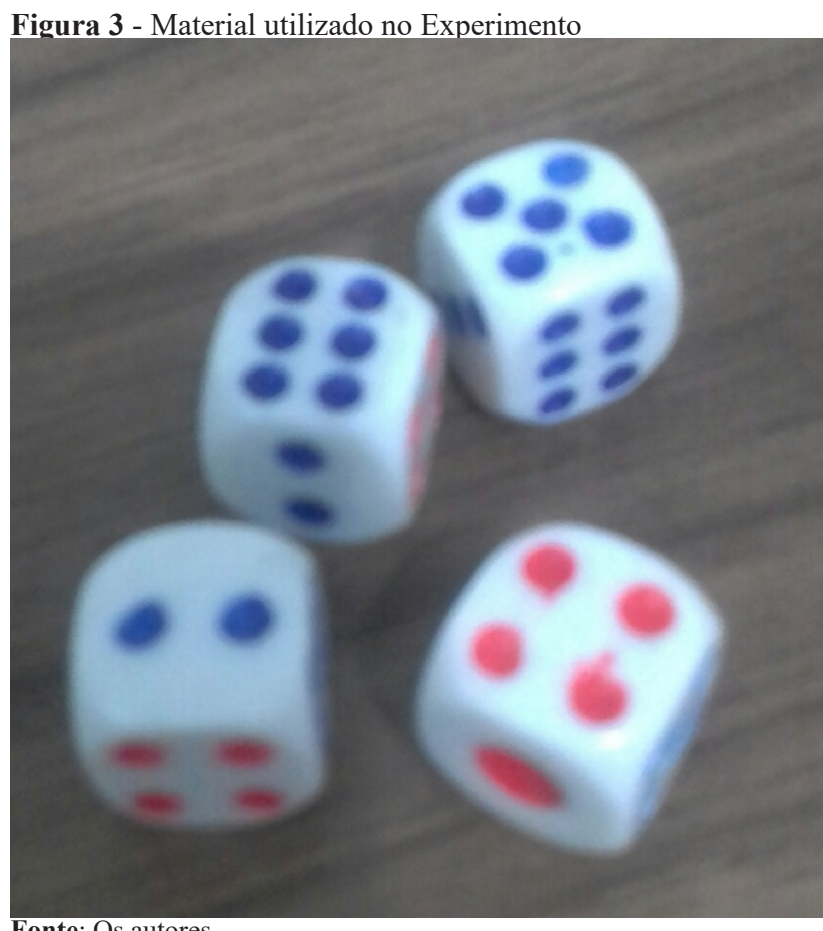

Fonte: Os autores.

A realização do experimento possibilitou captar os indicadores de presença de pensamento algébrico funcional nas estratégias utilizadas pelos participantes na resolução do problema proposto. Na Figura 3 é apresentado o material manipulativo utilizado no experimento, que se constitui de dados não viciados com seis faces numeradas de um até seis.

Participaram do estudo dez estudantes, individualmente. Ressalta-se que esta atividade foi realizada em uma turma com cerca de vinte alunos. No entanto, nem todos tiveram sua participação registrada devido a problemas técnicos ocorridos durante a gravação do áudio. Quando este problema foi solucionado, faltava realizar a atividade com dez estudantes, os quais consideramos, para fins de análise, os sujeitos da pesquisa.

A análise do material coletado a partir da realização do experimento foi realizada em cinco etapas: 1) categorização a partir das ações apresentadas pelas crianças; 2) destaque das relações entre categorias, a partir da hipótese inicial; 3) conferência geral para validação das categorias; 4) definição 
dos níveis de respostas; 5) análise das estratégias utilizadas pelos sujeitos de cada nível à luz da teoria dos campos conceituais (Vergnaud, 1990, 1997, 2009), com o intuito de caracterizar o pensamento algébrico nas situações de comparar apresentadas aos participantes.

Estes passos metodológicos de análise das entrevistas clínicas são baseados em Delval (2002) quando utiliza o MCMF, com exceção do último, que é proposto neste trabalho com o intuito de trazer elementos da teoria dos campos conceituas de Gérard Vergnaud (1990, 1997, 2009), afim de aprofundar a discussão sobre as estratégias algébricas utilizadas por estudantes dos anos iniciais em situações que envolvem a comparação entre medidas.

\section{Resultados e Discussão}

Nesta seção apresentamos alguns trechos transcritos das entrevistas realizadas durante a aplicação do MCMF, bem como a análise das estratégias utilizadas pelos estudantes. Seguindo a organização dos procedimentos metodológicos, dividimos a análise dos dados em cinco partes: 4.1 categorização das respostas; 4.2 relação entre categorias; 4.3 validação das categorias; 4.4 níveis de respostas; 4.5 teoremas-em-ação de Previsão de Resultados.

\subsection{Categorização das Respostas}

A partir da análise dos protocolos produzidos na coleta de dados, foram encontradas três categorias de respostas, denominadas respectivamente por Erro pela Soma (ES), Erro pelo Maior (EM) e Acerto (A). A construção de tais categorias se deu em função do tipo de raciocínio utilizado durante a realização do experimento. A seguir apresentamos trechos das entrevistas que ilustram as respostas dos dez estudantes participantes do estudo. Como os participantes não foram identificados, optamos por numerá-los na ordem de sucessão original das entrevistas.

Três alunos não souberam responder ou apresentaram respostas que se basearam exclusivamente no sorteio do número do dado (os estudantes 4, 7 e 9). Por isso, não apresentamos tais respostas nesta seção. Nos detivemos na classificação das estratégias que apresentaram algum tipo de causalidade, mesmo que não tenham atingido a resposta correta.

\subsubsection{Categoria Erro pela Soma - ES}

Nesta categoria se encontram as respostas de estudantes que consideraram a expressão a mais como indicativo de soma. Para estes estudantes, toda vez que a expressão a mais é enunciada em um problema matemático, deve-se realizar a operação de adição. Os diálogos a seguir ilustram esse tipo de pensamento ${ }^{2}$.

$[2]^{3} \mathrm{O}$ meu caiu, ..., é meu esse. (os dois sorteiam os dados).
O meu foi um. O meu foi cinco, né? Quanto ele é maior do que esse? Esse. Esse. Esse. Sim, Não. (apontando para o dado com a face cinco voltada para cima). Então, quanto ele tem a mais? Seis. Seis? É.

[3] Eu tirei um, tu tirou três não é? Aham. Quem tirou mais? Eu. Tu. Quanto a mais? Esse um, esse é três, então fica no quatro.

\subsubsection{Categoria Erro pelo Maior - EM}

Para os sujeitos desta categoria, a expressão a mais nos problemas de comparar apresentados é um indicativo que deve-se escolher o maior dentre os números sorteados nos dados. A seguir encontramos alguns recortes nos protocolos ilustrando esse tipo de raciocínio.

[1] O teu é três, e o meu quanto que é? Dois. Dois, né. Então quanto a mais tu tirou? Três. Três? É. Ok. Como é que tu sabe que é três? Tá ali. Bom, tu olhou no dado? É isso? É. Essa é a única forma? $\dot{E}$.

[6] Eu tirei dois e tu tirou cinco né? É. Quem tirou mais? Eu. Quanto a mais? Cinco. Esse mesmo resultado eu perguntei para um colega teu e ele disse que tinha dado três. Tu acha que ele pode tá certo? Três a mais não, é cinco.

[10] Quanto tu tirou? Três. Quanto eu tirei? Cinco. Quanto o meu dado tem a mais do que esse? (apontando para o dado com a face três voltada para cima). Cinco. Porque esse tem cinco, e cinco é mais. Em outra turma me disseram que nesse aqui tem dois a mais do que esse. Tu acha que o aluno acertou ou errou? Acho que, ..., acho que errou até.

\subsubsection{Categoria Acerto - A}

Esta categoria contempla estratégias que obtiveram sucesso na resposta, sem apresentar indícios de acerto por sorte ou devido a outro fator diferente de compreensão. Nessa direção, o entendimento do sujeito aconteceu através de uma previsão seguida por contagem, para chegar a resposta da situação proposta no experimento. $\mathrm{O}$ estudante 5 , inclusive, antecipou na sua resposta o que seria perguntado, seguindo o protocolo da entrevista, pois já disse antes de ser perguntado, quantos possuía a mais.

[5] Tirei três, e tu? Seis. Tô com três a mais.

[8] Quanto tu tirou? Quatro. E eu? Seis. Quanto tu tirou a menos? Dois.

\subsection{Relação entre as Categorias}

No experimento realizado procurou-se construir perguntas com uma estrutura semântica simples, o que não significa ser de fácil compreensão para a faixa etária dos entrevistados. Embora o alcance do pensamento das crianças entre seis e oito anos apresente transformações importantes, trata-se de um período de construção de importantes esquemas conceituais e da lógica, incluindo a antecipação do pensamento.

Como as falas e explicações dos estudantes apresentaramse de forma bastante clara, não tivemos dificuldades para categorizar suas respostas. Não foi possível constatar termos característicos nas respostas apresentadas em cada categoria, porém alguns procedimentos de manipulação com os dados e 
de explicação da ação realizada serviram como critério para determinar as categorias.

$\mathrm{Na}$ categoria ES, por exemplo, um procedimento muito comum realizado pelos estudantes era o de juntar os números dos dados para compor uma nova medida, sendo esta última entendida como o valor a mais perguntado.

$\mathrm{Na}$ categoria EM, notou-se que os estudantes não realizavam procedimentos envolvendo operações aditivas, adotando como critério de escolha para o número que tem quantidade a mais no dado, aquele que é maior. Destaca-se a convicção com que os estudantes defenderam seu ponto de vista nesta categoria. Quando confrontados com a opinião de outros estudantes, através da exposição de um raciocínio hipoteticamente diferente do seu, continuavam firmemente com a resposta que escolheram, não apresentando dúvidas sobre o próprio critério de identificação do número a mais.

Nas falas apresentas na categoria A, apesar de não estar explícito nos trechos selecionados, o principal procedimento adotado por esses estudantes foi a previsão seguida por contagem, efetuada nos dedos. Isso significa que os estudantes conseguiam prever o resultado da situação perguntada, e que, posteriormente as suas afirmações, realizavam a contagem para confirmar o resultado. A operação de subtração não foi utilizada por nenhum participante, sendo a contagem a principal estratégia.

\subsection{Validação das Categorias}

A fim de certificar o procedimento adotado para a análise dos resultados, optou-se pela verificação junto a um juiz, isto é, um sujeito que não é participante nem pesquisador relacionado com a pesquisa, e que pode julgar se as categorias construídas pelos pesquisadores estão adequadas. Este procedimento de validação é bastante utilizado em pesquisas que utilizam o MCMF e é descrito em detalhes por Delval (2002). Para isso, uma estudante de Licenciatura em Matemática que não participou do estudo foi consultada para validar as categorias. Inicialmente apresentou-se à licencianda o nome e as características de cada categoria, sem a presença dos trechos das entrevistas.

Posteriormente, foram apresentados três trechos das falas a essa juíza, um de cada categoria. Foram selecionadas, respectivamente, as falas dos estudantes 2,6 e 8, perguntandolhe em seguida, as categorias nas quais essas falas poderiam ser alocadas. A categorização realizada pelos autores da pesquisa coincidiu com a categorização realizada pela juíza.

Mesmo alterando a ordem das falas, as categorias foram recuperadas na etapa de validação, o que indica que os critérios utilizados na construção das mesmas possuem baixo grau de subjetividade.

\subsection{Estrutura de Organização das Respostas}

Para entender como pensam os estudantes participantes em situações de comparar, fez-se uma organização em relação a estrutura de pensamento utilizada. Nessa organização foram identificados dois níveis de respostas: Nível 1, no qual não existe previsão de resultados; e o Nível 2, no qual existem estratégias elementares de previsão de resultados. É importante esclarecer que na análise dos dados não tivemos a intensão de classificar cada sujeito em um determinado nível, mas sim de organizar os raciocínios em função de características comuns.

O Nível 1 caracteriza-se por entendimentos que apresentaram resultados não corretos. Durante o processo de comparar os números dos dados lançados, pode-se observar que os raciocínios apresentaram-se em duas direções: 1A, no qual a adição é a operação associada a expressão a mais, e 1B, no qual a operação de tomar o número maior está associada com a expressão a mais.

No Nível 1A, há um conflito lógico no uso da palavra mais, a qual também é utilizada para indicar a operação de adição. Nesse nível, a criança ainda não diferencia a previsão de resultados, ainda que a palavra mais não esteja na mesma disposição sequencial de problemas puramente aditivos. $\mathrm{O}$ estudante 3, por exemplo, ao tentar relacionar os números dos dados, fala: "esse um, esse é três, então fica no quatro".

No Nível 1B os estudantes associam a palavra mais com a operação de tomar o número maior, como o estudante 10 que afirma que "cinco é mais". Esta é uma pequena evolução em relação ao Nível 1A já que a palavra mais deixa de estar diretamente associada com a adição e passa a ser associada com outra operação, ainda que não haja uma precisão maior, com relação aos problemas de comparar.

Observa-se que os estudantes com características de raciocínio de Nível 1 ainda não desenvolveram a habilidade de antecipação e conservação de pensamento. Isso significa que seu pensamento ainda não apresenta a característica de ser reversível. Reversibilidade é a capacidade de pensar simultaneamente o estado inicial e o estado final de alguma transformação que o sujeito efetua sobre os objetos (La Taille, 1992).

A reversibilidade refere-se à habilidade de revisitar as etapas do pensamento, realizando mentalmente as ações (Bertolucci, 2009). Estas ações podem ser opostas simultaneamente. Na ação física, realizada através de algum material, não é possível fazer duas coisas opostas ao mesmo tempo. Entretanto, no plano mental, isto é possível quando o pensamento se tornou bastante móvel para ser reversível (Kamii, 1984). A autora explica que "somente quando as partes puderem ser reunidas na mente é que a criança poderá ver que há mais animais do que cachorros" (p.23).

Não podemos afirmar que os sujeitos do Nível 1 não realizam nenhuma ação reversível. Entretanto, ao serem questionados sobre quanto a mais é o resultado de um dado em relação à outro, no nível $1 \mathrm{~A}$ os sujeitos relacionaram à operação de adição, realizando a soma dos valores apresentados. No nível 1B, atribuíram a expressão mais com a operação de tomar o número maior. Observa-se que no processo de ida e volta das ações, no caso a operação de antecipação do resultado, não ocorreu no plano mental dos 
sujeitos

Percebe-se que os estudantes consideraram a situação estática, encaminhando a explicação em função de características externas, mais do que em função das transformações que levam de uma situação a outra, corroborando com Inhelder e Piaget (1976). Em nosso estudo, tal transformação refere-se a operação de saber quanto a mais tem um dado em relação à outro.

Ainda que este estudo não se propõe a identificar qual estádio de desenvolvimento cognitivo encontram-se os estudantes, de acordo com a teoria Piagetiana (Inhelder \& Piaget, 1976), o que caracteriza a passagem do pensamento pré-operatório para o operatório é a reversibilidade do pensamento. O que se observa no Nível 2 é a possibilidade de antecipação do resultado, ou seja, a existência de inversão da operação.

No Nível 2, os estudantes apresentam a estratégia previsão seguida por contagem, descrita em detalhes no trabalho de Beck e Silva (2015). Segundo os autores, esta estratégia se caracteriza pela noção de que há uma regra de associação entre as grandezas que pode antecipar o resultado sem a necessidade de processos de cálculo mais extensos. Esta estratégia está baseada na contagem, isto é, não faz uso de operações aritméticas mais sofisticadas como adição ou subtração. Isto mostra que é possível que o desenvolvimento da previsão de resultados aconteça, mesmo antes do aprendizado de operações aditivas.

\subsection{Teoremas-em-Ação de Previsão de Resultados}

Com base nos níveis de respostas apresentados na seção 4.4, podemos destacar que foram constatados, neste estudo, dois teoremas-em-ação em situações de comparar: aritmetização indiscriminada (Nível 1) e previsão seguida por contagem (Nível 2).

A aritmetização indiscriminada se caracteriza pelo uso de operações aritméticas, como a adição e tomar o número maior, mesmo em casos onde ela não é eficaz. Os teoremasem-ação do Nível 1 de respostas deste estudo constituem um exemplo desse uso indiscriminado.

Com relação ao teorema-em-ação previsão seguida por contagem, ressaltamos que não há diferença das estratégias constatadas nesta pesquisa, das estratégias apresentadas no trabalho de Beck \& Silva (2015). Nesse trabalho os autores destacaram ainda que problemas dessa natureza apresentam potencial para desenvolver na criança a habilidade de "prever resultados desconhecidos usando dados conhecidos". Essa habilidade constitui um dos aspectos indicados por Blanton \& Kaput (2005) para o desenvolvimento do pensamento funcional, uma das duas vertentes do pensamento algébrico.

Partindo da Teoria dos Campos Conceituais, a previsão seguida por contagem pode ser assumido como um invariante operatório do pensamento algébrico. Por isso, o presente estudo corrobora com a caracterização deste teorema-em-ação construída naquele no trabalho de Beck \& Silva (2015).

\section{Conclusão}

Tendo em vista que o objetivo deste trabalho era rastrear traços de pensamento algébrico funcional em situações de comparar, podemos dizer que a previsão seguida por contagem, estratégia já observada em trabalhos precedentes, também foi utilizada pelos sujeitos participantes da presente pesquisa.

Esta semelhança de conclusões entre pesquisas, com relação ao uso da previsão de resultados, indica que é possível identificar estratégias cognitivas que apresentam traços de pensamento algébrico funcional, mesmo com estudantes que estão iniciando a vida escolar. No caso desta pesquisa, estudantes do primeiro ano foram capazes de propor estratégias de resolução, sendo que alguns inclusive obtiveram sucesso com uso de suas estratégias.

A novidade que encontramos, em termos de estratégias, foi o uso indiscriminado de operações aritméticas, isto é, operações como adição e tomar o número maior foram utilizadas, sem uma análise mais aprofundada da estrutura do problema, e do significado de expressões tais como a mais e a menos nos enunciados. Ressalta-se que a adição, de certa forma, foi considerada na análise a priori da atividade por já apresentar precedentes na literatura, mas tomar o número maior foi uma reposta utilizada de modo emergente, que causou surpresa aos pesquisadores.

Ainda que algumas estratégias não tenham sido bemsucedidas, elas são importantes para constatar que o pensamento algébrico se desenvolve de forma concomitante ao pensamento aritmético, o que vai de encontro ao mito da anterioridade da Aritmética em relação à Álgebra. Observamos também que trabalhar a reversibilidade de pensamento mostrase como uma importante habilidade a ser desenvolvida junto à introdução da Álgebra.

Os resultados deste estudo mostram que o desenvolvimento de estratégias que envolvem o pensamento algébrico não depende, necessariamente, do domínio completo de operações aditivas. De acordo com estudos precedentes, e com os resultados da presente pesquisa, podemos dizer que a contagem é um procedimento fundamental para que habilidades algébricas possam ser trabalhadas desde os anos iniciais de escolaridade.

\section{Referências}

Beck, V. C., \& Silva, J. A. (2015). Pensamento Algébrico Funcional: O Uso da Previsão de Resultados em Problemas Aditivos. Teoria e Prática da Educação.18, 69-78. doi: https:// doi.org/10.4025/tpe.v18i2.31445

Bertolucci, C. C. (2009). Noções de Infinito Matemático em Adolescentes e Adultos. Dissertação de Mestrado. Programa de Pós-Graduação em Educação, Universidade Federal do Rio Grande do Sul, Porto Alegre.

Brasil (2014). Pacto Nacional pela Alfabetização na Idade Certa: Apresentação. Brasília: MEC, SEB.

Blanton, M., \& Kaput, J. (2005). Characterizing a classroom 
practice that promotes algebraic reasoning. Journal for Research in Mathematics Education. 36(5),412-446. doi: $10.2307 / 30034944$

Brasil (2020). Base Nacional Comum Curricular. Disponível em: <http://basenacionalcomum.mec.gov.br/>. Acesso em: 6 jun. 2020.

Carpenter, T. P., Levi, L., Franke, M. L., \& Zeringue, J. K. (2005). Algebra in the elementary school: developing relational thinking. ZDM - The International Journal on Mathematics Education. 37(1), 53-59. doi: https://doi.org/10.1007/ BF02655897

Delval, J. (2002). Introdução à prática do método clínico: descobrindo o pensamento das crianças. Porto Alegre: Artmed.

Disessa, A. A. (2007). An Interactional Analysis of Clinical Interviewing. Cognition and Instruction, 25(4), 523-565. doi: 10.1080/07370000701632413

Falcão, J. T. R. (2003). Alfabetização Algébrica nas Séries Iniciais. Como Começar?. Boletim GEPEM, (42), 27-36.

Fujii, T., \& Stephens, M. (2008). Using number sentences to introduce the idea of variable. In: C., Greenes, \& R., Rubenstein. Algebra and algebraic thinking in school: Seventieth Yearbook, (127-149). National Council of Teachers of Mathematics. VA, Reston.

INEP (2020). Provinha Brasil. Disponível em: <http:// provabrasil.inep.gov.br/web/guest/provinha-brasil>. Acesso em: 6 jun. 2020.

Inhelder, B. \& Piaget, J. (1976). Da lógica da criança a lógica do adolescente. São Paulo: Pioneira.

Kamii, C. (1984). A criança e o número: Implicações Educacionais da Teoria de Piaget para a Atuação junto a escolares de 4 a 6 anos. Campinas: Papirus.

Kieran, C. (2007). Developing algebraic reasoning: The role of sequenced tasks and teacher questions from the primary to the early secondary school levels. Quadrante, 16(1), 5-26.

La Taille, Y. (1992). Desenvolvimento do juízo moral e afetividade na teoria de Jean Piaget. In: La Taille, M. K., Oliveira, , H. Dantas. Piaget, Vygotsky, Wallon: teorias psicogenéticas em discussão. São Paulo: Summus. p. 47-74.

NCTM. Principios e Normas para a Matemática Escolar. (2008). Lisboa: APM.

Ponte, J. P. \& Velez, I. (2011). Representações em tarefas algébricas no $2^{0}$ ano de escolaridade. Boletim GEPEM, (59), 53-68.

Silva, D. P. \& Savioli, A. M. P. D. (2012). Caracterizações do pensamento algébrico em tarefas realizadas por estudantes do Ensino Fundamental I. Revista Eletrônica de Educação, 6(1), 206-222. doi: http://dx.doi.org/10.14244/19827199387

Stephens, M., \& Wang, X. (2008). Investigating some junctures in relational thinking: a study of year 6 and 7 students from Australia and China. Journal of Mathematics Education. 1(1), 28-39.

Vergnaud, G. (2009). A criança, a matemática e a realidade: problemas do ensino da matemática na escola elementar. Curitiba: UFPR.

Vergnaud, G. (1990). La théorie dês champs conceptuels. Recherches em Didactique dês Mathématiques. 10(2,3), 133170.

Vergnaud, G. (1997). The nature of mathematical concepts. In: T. Nunes, \& P.,Brynt. Learning and teaching mathematics, an international perspective. Psychology Press. 